\title{
Hidden Costs? Malpractice Allegations and Defensive Medicine Among Cardiac Surgeons
}

\author{
Marco Huesch \\ Duke School of Medicine \& \\ Fuqua School of Business \\ Barak Richman \\ Duke Law School \& \\ Fuqua School of Business
}

\begin{abstract}
This article evaluates the impact of private allegations of malpractice against cardiac surgeons on their patients' outcomes and characteristics. While tort law may impact observable physician costs, malpractice allegations also impose hidden costs that could also affect physician behavior. We employ a large and multi-year panel dataset and patient-level analysis to ascertain whether malpractice allegations influence a surgeon's practicing behavior. Using a generalized difference-in-difference model that controls for unobserved patient heterogeneity, clustering of patients within surgeon offices, contemporaneous expected risk, and other patient variables, we measure whether an allegation of malpractices affects a physician's service intensity and use of healthcare resources. Our results find no evidence that physician behavior was sensitive to allegations, findings of or settlements of malpractice claims. This is consistent with either low levels of defensive medicine in this specialty or pervasive and persistent practicesincluding defensive medicine - that are not significantly impacted by actual claims filed.
\end{abstract}




\section{INTRODUCTION}

Tort law reform that limits recoverable damages is predicated on the theory that reducing the costliness of negligence ought to reduce the practice of defensive medicine and reduce healthcare delivery costs. Yet while recent tort law reforms appear to have had a strong impact on reducing malpractice insurance premia, it has had little impact reducing the practice of defensive medicine. To reconcile these findings, Danzon (2000) suggested that the hidden costs of malpractice, such as psychic costs and loss of time defending malpractice allegations, are the primary drivers of defensive medicine, whereas tort reform only reduced observable costs.

If the Danzon hypothesis is true, then the introduction of hidden costs would increase defensive medicine and change physician behavior even before observable public, monetary and reputational costs occur following the adjudication or settling of claims. We empirically test the impact of such private allegations of physician malpractice on the services the accused physicians deliver to patients and the consequent outcomes those patients exhibit.

\section{HIDDEN AND OBSERVABLE COSTS IN MALPRACTICE CLAIMS}

\section{A. Tort Law and Defensive Medicine}

Although tort law, in theory, should incent the provision of the appropriate standard of healthcare, many healthcare professionals and policymakers believe that the tort system instead induces the over-provision of care. Specifically, recent scholarship has uncovered strong empirical evidence that the over-provision of care at the intensive margin and under-provision at the extensive margin may be unintended and costly 
consequences of tort law (Shavell, 1984; Kessler \& McClellan, 1996, 1997; Morrisey et al., 2008).

Such 'defensive medicine', on the part of rational providers can be explained by uncertainty in the process of assigning costs to individual providers (Morrisey et al., 2008). Anecdotal and empirical evidence exists that the medical negligence system operates poorly (Cranberg et al. 2007), contributing to such uncertainty (although many find that malpractice judgments accurately reflect malpractice (Studdert et al. 2006)). The tort system may also impose costs that are above those associated with compensation, including reputational costs and the costs of defending suits. Defensive medicine then reduces the risk of future litigation events, a plaintiff's likelihood of success, and the defendant's costs of litigation.

Concern over costly 'defensive medicine' has led many legislatures to pass 'tort reform' laws that, among other things, limit the damages that can be awarded to tort victims (Avraham, 2007). Reducing the costliness of negligence ought to thus reduce the practice of defensive medicine and reduce healthcare delivery costs (Hyman, 2007; Dranove \& Gron, 2005; Mello et al., 2004). A separate objective of tort reform is to reduce the average premia of malpractice insurance as a direct consequence of lower total awarded damages (Black, Hyman et al., 2008). Anecdotally, sufficiently high rates of malpractice insurance may drive physicians out of delivery markets, although empirical evidence suggests this is a low risk (Yang et al 2008; Black, Hyman et al., 2008).

Yet efforts at tort law reform appear to have had small impacts on the practice of defensive medicine (Studdert et al, 2004; CBO, 2004; Bobvjerg \& Tancredi, 2005; Hellinger \& Encinosa, 2006; Nelson et al., 2007; Sloan \& Schadle, 2009; Waters, 2007), 
while having strong impacts on the level of malpractice insurance premia (Kessler \& McClellan, 1997; Morrisey et al., 2008; Sloan, 2003; Cline \& Pepine 2004).

These findings need to be reconciled. One explanation is that physician practice patterns are persistent over time and insensitive to the threat of tort suits,, although physician behavior has been shown to be responsive to therapeutic and incentive norms (Frank \& Zeckhauser, 2007), militating against an explanation of simple persistence of practice. Indeed, tort law reform with a potentially negative financial impact on physicians, such as the reform of the joint and several liability rules, has indeed been shown to have the expected effect of more cautionary physician behavior (Currie \& Macleod 2008). A related but more limited possibility is that defensive medicine is pervasive and is supported by both therapeutic norms and by financial incentives, even when the costs of negligence are reduced. And yet another potential explanation is that the link between actual malpractice and an ultimate adverse judgment is sufficiently tenuous (Adams \& Garber 2007), such that rational physicians do not change behavior in response to fears of future claims.

\section{B. The Hidden Costs of Malpractice Claims}

In this paper, we investigate an alternative explanation, suggested by Danzon (2000) and raised again by Morrisey et al. (2008), that the threat of hidden — rather than observable — costs of malpractice are the primary drivers of defensive medicine.

This explanation supposes that a meaningful proportion of the overall expected cost of malpractice claims - that is, the costs to physicians that physicians thereby seek to avoid - is associated with the mere event of a tort action being commenced. Such costs 
may, for example, include the non-financial costs of stress and the cognitive load of defending litigation (Morrissey et al, 2008), the lost time and associated direct financial costs from lost patient revenue or failure to develop a practice, and other reputational costs. Additionally, these hidden costs could be heightened by common errors that take place in unsuccessful settlement negotiations (Kiser et al 2008). They may also include lost time and the associated direct financial costs from lost patient revenue or failure to develop a practice. Crucially, such costs are neither insurable nor recoverable, are borne entirely by the defendant provider and commence immediately on private receipt of an allegation of malpractice.

Private and uninsurable costs of this nature could simultaneously explain both the reduction in malpractice premia and the small or insignificant impact on defensive medicine. Reform tends most directly to reduce a defendant's insurance costs conditional on litigation than to reduce the likelihood of litigation. By construction, capped awards or collateral source offsets reduce payouts conditional on litigation (Black, Hyman et al., 2008). These reforms, however, do nothing to change the short-run hidden costs, including the stress and time lost time from dealing with a filed claim. If these unobservable costs affect physician behavior, then we are more likely to detect behavioral changes following the initiation of malpractice claims (which are communicated privately) rather than following more public events, such as the filing of a lawsuit or the announcement of a settlement or judgment.

\section{Prior Research}


We argue that the 'private' costs of malpractice are separate from and in addition to any later 'public' costs occasioned by reputational damage. Dranove et al (2008) investigate such public costs and find that publicly knowable events such as suit filings are associated with a less attractive payor mix in the twelve months subsequent to an obstetrician being sued. Like us, Dranove et al (2008) assume that claimed malpractice has adverse effects on a physician, regardless of final disposition of the claim. We also consider the filing of a lawsuit per se as a negative reputational signal even though in our setting two of every five final decisions are not for the plaintiff and did not involve payment or court proceedings.

Unlike us, Dranove et al's model requires well-informed consumers and/or insurers observing external data and then rapidly changing preferences over providers or changing selective contracts with providers. Instead, we assume that a reported allegation of injury is immediately observable to the physician and occurs long before the public signal, if any, of a suit. For example, in our data, there is almost 1 year between the private reporting of an alleged claim and the public filing of a lawsuit. In more than 1 in 5 claims in our sample, no lawsuit is filed and claims instead are dropped, settled or arbitrated. We assume that psychic costs occur following a claim even when no lawsuit is filed, but we note that this area is understudied, and the only empirical evidence through physician surveys have not supported this (Glassman et al, 1996).

In this article, we seek to show that such private costs exist and have meaningful, exogenous effects on physician behavior. Our study uses patient-level data, which controls for patient heterogeneity, and examines whether malpractice claims induce Florida cardiac surgeons to increase the intensity and costs of health services to 
subsequent patients. Gimm (2010) employed a similar physician-level model with Florida data and concluded that privately communicated claims did not affect C-section rates or the caseloads of Florida obstetricians. But because of the limited spectrum of patients, that study was not ideal to control for patient heterogeneity, the failure to reject the null hypothesis of no impact may be due to omitted variables. Since prior work has shown that there are complex relationships between typical malpractice risk in a geography and patient-level outcomes (Dhankhar et al 2007), patient-level data with patients exhibiting a diverse spectrum of conditions offers a better opportunity to test for hidden costs.

We investigate these hypotheses using a detailed administrative discharge dataset comprising more than 220,000 cardiac surgeries performed by 314 operating cardiac surgeons in Florida between 1998 and 2006. Of these surgeons, 113 had patients who initiated malpractice claims in 1998-2006 that were subsequently reported to the Office of Insurance Regulation in Florida. For each patient we have data on pre-existing risk factors, payor status, and in-hospital outcomes. We link surgeon identifiers to publicly available data on closed allegations of injury submitted by malpractice insurers to the Florida Office of Insurance Reform between 1994 and 2009.

Malpractice claims data from the Florida Office of Insurance Regulation are ideal to test this hypothesis because for each settled malpractice claim we have dates for each of the key events: the alleged occurrence, the report of alleged malpractice, the suit filing, and the disposition of the case. We also have data on key outcomes, including the dispute resolution process, decision, and financial awards if any. We construct measures of lagged claim events (alleged occurrences, reports, filings and final dispositions) for 
each surgeon over time and relate this to his or her contemporaneous patient-level charges, outcomes, payor status and ex ante patient risk.

Our main analytical approach uses a general difference-in-difference design to test the effects of allegations on patient-level charges and outcomes. We expect that more charges will be incurred without changes in outcomes in patients seen following the private report of an alleged injury. We do not expect that the filing of a lawsuit will lead to any changes, since we hypothesize that these have already been triggered by the earlier private report of injury. Conversely, we expect the final disposition of an allegation to be followed by lower incurred charges. Crucially, we expect that a decision in favor or against the defendant at final disposition should make no difference to the measures of provider behavior we use, since any judgments are insurable costs.

\section{METHODOLOGY}

\section{A. Patient Level Data}

Our patient-level data is from the Agency for Health Care Administration in Florida, and represents all 229,153 records discharges for CABG performed in stateregulated hospitals in the 36 quarters in 1998-2006. We excluded patient records where the hospital had admitted less than 5 records over the panel (20), where the patient's age was less than 18 years (22), where the admitting hospital was unable to be matched to any known facility characteristics data (33), and where the operating medical practitioner was only observed one quarter $(1,377)$. Almost all of these were singleton observations and likely data entry errors. 
A further 1,661 patient records were discarded where the average number of cases per period per was 1 or less. A further 4,713 observations were dropped where publicly available information from the Florida department of health confirms that the operating medical license was a non-surgeon (e.g. an internist, or a cardiologist, or a family physician). These may be due either to erroneous data entry or assistants wrongly entered as the operating surgeon, or cases that had both major medical and surgical treatment.

Finally, records were merged for 6 clearly identified (name, history) surgeons who held both a "Medical Faculty Certificate" and a "Medical Physician" license over the panel, treating patients under both licenses. This exclusion and validation reduced our data to 221,327 admission and 397 operating surgeons.

\section{B. Surgeon and Claim Level Data}

Our surgeon-level claims data are the reports of alleged error, omission or negligence by insured doctors held by the Office of Insurance Regulation in the Florida Department of Financial Services. In our data, insured doctors include allopathic physicians (i.e. MDs) as well as osteopathic and podiatric physicians. None of the 6 osteopathic medical degree holding cardiac surgeons (with 1901.x license identifiers) or the one podiatric medical degree holding cardiac surgeon (2101.x) or any surgeons practicing exclusively under a medical faculty licensure (1508.x) had any closed claims recorded in this data. Most of these claims led to the filing of a lawsuit, most of which did not go to court (see Table 1).

$<$ INSERT TABLE 1 ABOUT HERE $>>$ 
We consider only alleged injuries categorized as "significant harm" or worse. Specifically, these were death of the patient, grave harm (quadriplegia, severe brain damage, lifelong care or fatal prognosis), major harm (paraplegia, blindness, loss of two limbs, brain damage.) and significant harm (deafness, loss of limb, loss of eye, loss of one kidney or lung). The OIR data contained additional closed claims representing substantially less severe injuries. We chose not to include these to preserve homogeneity in the claim unit of analysis and since we expect the more severe claims to have the most impact on behavior. See https://apps.fldfs.com/PLCR/Search/MPLClaim.aspx for more details.

The malpractice claims data includes four sequential categories of events related to malpractice claims (Figure 1). These comprise of (i) alleged injury occurrence detailing date, place, nature and allegedly responsible (retrospectively communicated at the time of the report), (ii) report of claim to a surgeon's malpractice insurer and to the surgeon, (iii) filing of suit, if any, and (iv) final disposition of the claim.

\section{$<$ INSERT FIGURE 1 ABOUT HERE $>>$}

The data affords an opportunity to examine behavioral changes following the reporting of a claim while controlling for any subsequent suit or award. We thus are able to test the independent effect of the reporting of such a claim and its associated costs, such as the stress of resolving an ongoing action, costs (both dollars and time spent) disputing the claim, and other psychic and monetary costs. These costs are thus separated 
from the more conventional direct (i.e. damages) and indirect (i.e. reputational harm) costs of malpractice litigation. These more conventional direct and indirect costs were investigated by Dranove et al. (2008) who find that publicly knowable events such as suit filings are associated with a less attractive payor mix in the twelve months subsequent to an obstetrician being sued.

Of the 397 cardiac surgeons in our panel, 250 have no closed claims recorded at all in the fifteen-year interval from 1994 to 2009 spanned by our malpractice insurance surgeon-level data. A further eleven surgeons have all their closed claims comprise events which all happened outside the nine year interval from 1998 to 2006 spanned by our patient-level admission data. We restrict our analysis to procedures occurring no later than 2006 because many claims require as many as three years to resolve and claims enter the Florida database only once closed, thus malpractice claims reported in 20072009 are unlikely to be in the data.

As a preliminary matter, we confirm a strong positive association between a physician's number of closed claims and his/her total volume (Pearson correlation 0.273, p<.001). We excluded 83 surgeons on the basis of implausibly low annual volume $(<10$ cases) and low participation (e.g. one quarter a year for three years). These surgeons are unrepresentative of the typical surgeon. They are likely to have major non-Floridian practices (e.g. in Georgia or Alabama, or if practicing at Mayo's Florida campus they may practice further afield at the main Rochester, MN campus), or practicing concurrently in non-state-regulated hospitals (e.g. the Veterans' Administration hospitals). Our data use agreement forbids us from contacting the surgeons to explore this. Compared to the included surgeons, the excluded surgeons had lower average settled 
claims ( 0.45 versus 0.67 ; two-tailed t test $p=.076)$ and lower average number of events observed in the panel $(0.82$ versus 1.26 ; two-tailed $\mathrm{t}$ test $p=.038)$. These small differences were not consistent with an alternative explanation that the excluded surgeons had exited the panel as a result of alleged injuries sustained by their patients.

The effect of these exclusion criteria was to reduce total surgeons to 314 , and the number of patient records to 220,843 . The total number of closed claims observed is 211 claims, and 113 surgeons had at least one closed claim from which 89 surgeons experienced at least one suit.

We reconstruct a summary dataset of malpractice claims using the surgeon*quarter as unit of observation with the twelve month lagged total of each of the four malpractice events. This lagging further reduced final regression observations to 185,849 patient records and 296 surgeons. This summary data, reported in Table 2, includes alleged occurrences, of private reports, of filed suits, and of final dispositions (which were distinguished by decisions for the plaintiff or for the defendant). We observe but don't analyze the size of monetary damages.

\section{$<<$ INSERT TABLE 2 ABOUT HERE $>>$}

We merged these data with the patient-level data: for each patient admission we are able to relate patient-level dependent variables to lagged surgeon-level flows of malpractice 'events'. We present surgeon-level summary histograms of lagged event flows in Table 3 and Figures 2a-e, respectively. 


\section{$<$ INSERT FIGURES 2a-e ABOUT HERE >>}

\section{Variables}

We study the incidence of the following binary events: prolonged mechanical ventilation, in-hospital mortality, discharge destination not home. The latter includes all live discharges who have some degree of home healthcare, or who were discharged to sub-acute and convalescent hospitals or nursing homes. Additionally we examined the following continuous events, using the natural logarithmic transformation of length of stay, operating room, non-operating room and total charges. ${ }^{1}$ These are assorted measures of treatment intensity and serve as our dependent variables.

${ }^{1}$ We did not have data on hospital reimbursements for claimed services, but the discharge data did contain itemized charges representing the product of list prices per service and a range of itemized services. As long as we control for unobserved heterogeneity among individual hospitals in setting such charges, and for secular trends in the list prices, these charges likely amount to an accurate measure of hospital-site service intensity. We do not deflate these charges for several reasons. Our use of calendar fixed effects should control for statewide secular trends, and our use of hospital fixed effects mitigates some time-invariant unobserved heterogeneity in setting charges at the individual hospital level. Another reason not to deflate these charges is that they do not represent actual cash flows, but rather list prices. It is not immediately clear whether inflation in list prices tracks the producer price indexes that could be used for deflation purposes. 
We also computed a measure of ex ante risk by fitting a parsimonious logit regression on the binary outcome of in-hospital death controlling for the independent variables below (pseudo $\mathrm{R}^{2}$ of 0.18 , C-statistic of 0.83 ). The high area under the receiver operating curve suggests some over-fitting: that is, some of the covariates are possibly ex interim correlates of in-hospital mortality, as opposed to ex ante predictors. The predicted values from this regression for all patients identify changes in the risk profile of a surgeon's practice.

We utilize a large number of control variables from the administrative discharge data. Patient demographics (age, gender, non-white race), acuity (emergency presentation, transfer from another hospital), and payor status (government payor) help control for patient morbidity. We also link patient county of residence information to 2005 Census Bureau data on county proportions over 65 years, below poverty level and with bachelor degree, as well as median family income. There were also a large number of comorbidities (plausibly present at time of admission, although this is not known for sure).

To these focal variables we add one more control: the lagged number of cases the surgeon performed in the prior twelve months before the current quarter of the patient's admission. We do this to ensure that experience or scale economies do not confound the effect of malpractice allegations.

\section{Statistical Model}

We specified a reduced form model of the impact of lagged malpractice allegations on aspects of a surgeon's current patient admission. Our patient-level 
regressions are linear probability models for binary dependent and ordinary least squares for continuous dependent variables. In unreported analyses we also specified probit models for the binary dependent variables, but these did not qualitatively change the reported results.

For patients indexed by $i$, treated by operating surgeon $s$, in hospital $h$ admitted in quarterly period $q$ of year $t$ we estimate the following using ordinary least squares with robust standard errors clustered by operating surgeon:

$$
y_{i s h q}=\alpha+\beta X_{i}+\gamma X_{s}+\zeta_{h}+\zeta_{t}+\varepsilon_{i h q}
$$

The to-be-estimated vector $\gamma$ estimates the marginal effects of the focal variables of interest $X_{s}$, a $(5 \times 1)$ vector with generic element $\Sigma_{j=1}^{4}\left(L_{q-j}\right)$, where $L$ represents a quarterly flow of cases, alleged occurrences of malpractice, reports of alleged malpractice, malpractice suits filed and closed claims, respectively.

Independent variables comprise calendar year fixed effects $\zeta_{t}, 74$ hospital fixed effects $\zeta_{h}$ as well as a vector of patient controls $X_{i}$ (age, gender, non-white race, emergency presentation, transfer from another hospital, government payor, a large number of comorbidities and several county-level ecological variables from 2005 Census Bureau data on county proportions over 65 years, below poverty level and with bachelor degree, as well as median family income.).

Table 3 summarizes patient-weighted means of dependent and focal independent variables. Covariates and summary statistics are shown in Table 4, and a linear regression 
of these on in-hospital mortality showed no substantial multicollinearity (maximum VIF of 4.4, mean VIF of 1.4).

$<<$ INSERT TABLE 3 ABOUT HERE >>

$<<$ INSERT TABLE 4 ABOUT HERE >>

Our identification strategy exploits cross-sectional variation only. If patients select surgeons on the basis of publicly observable information on $L$, then an omitted variable bias may impact our estimates of $\gamma$. Since our interest is in privately-known surgeon-level events, this source of potential bias may not be too serious.

However, if a surgeon chooses to treat patients with lower risk (and hence with exogenously lower charges and better outcomes) after some event in $L$, then clearly $\gamma$ could be biased towards zero. We computed a measure of ex ante risk by fitting a parsimonious logit regression on the binary outcome of in-hospital death. We then checked for changes in patient risk, treating the ex-ante patient expected risk as a dependent variable analogously to the other dependent variables, but found no evidence of such changes (see Table 5, first column). Ideally, we should like to instrument for the events in $L$, but we were not able to conceive of a suitably exogenous proxy for individual surgeon allegation susceptibility.

We used Stata v10 for all data management and statistical analyses. We considered $p$ values of 0.05 significant and report only two-sided tests. We report estimated parameters both with robust standard errors and with robust standard errors 
clustered by operating surgeon. We did not correct for multiple comparisons (Rothman 1990). Our institution's Health System Institutional Review Board approved this study.

\section{RESULTS}

In Table 5 we report the marginal impact of a surgeon's additional claim event in the twelve months prior to the admission of the current patient. Columns represent separate regressions on separate dependent variables. We suppress reporting of the control covariates. Our measure of lagged cases (representing either or both of experience or scale economies) was highly significant and associated with a reduction in length of stay and hospital charges, and a reduction in the probability of prolonged mechanical ventilation, death in-hospital and discharge elsewhere than directly home.

\section{$<<$ INSERT TABLE 5 ABOUT HERE $\gg>$}

However, our focal variables of lagged malpractice events - whether private occurrences or reports, or public filings and dispositions - were not consistently associated with any of the patient outcomes in Table 5. Given the number of comparisons, the four coefficients estimated at $p$-values just below and just above .05 are likely due to chance alone. In particular, we find no evidence that the private occurrences and private reports of alleged malpractice impact patient charges.

The outcomes we investigate in Table 5 span both the mortality (averaging 3.8\%) and serious morbidity in cardiac surgery. It is well-known that as many as 3\% of CABG patients suffer strokes, around $2 \%$ experience kidney damage severe enough to require 
dialysis, and a further $3 \%$ survive a prolonged chest wall wound site infection (Eagle et al, 2004). In the panel, the incidence of these unobserved major morbidity events may lead to longer length of stay (average 10.2 days), discharge elsewhere than home (20.8\%), and prolonged mechanical ventilation greater than 96 hours $(2.9 \%)$. We found no evidence that any patient outcomes were affected by any of the sequence of events from alleged occurrence through to final disposition.

This is fails to support the putative mechanism of private stress and distractions causing defensive medicine (Danzon 2000). On the other hand, publicly observable signals of lawsuits also have no apparent impact on treatment service intensity either, unlike in Dranove et al's (2008) setting.

\section{< INSERT TABLE 6 ABOUT HERE >>}

In Table 6, we examine whether the payor status of the current patient was associated with lagged malpractice allegations on the part of the patient's surgeon. After the private alleged occurrence of malpractice in the prior 12 months before the quarter of the patient's admission, a patient was slightly less likely to have private indemnity insurance $(p<.05)$. After closed claims decided or settled against the surgeon, there was a slight reduction (increase) in the probability that a patient had PPO (HMO) insurance, both $p<.05$.

Finally, following prior scholarship (Dranove et al., 2008; Gimm, 2010), we also constructed physician-level models in addition to the patient-level models above. Prior work used linear regression in surgeon-level aggregate analyses to relate public 
malpractice suit filings to subsequent changes in surgeon caseload and payor composition, and has also examined the correlation between malpractice events within a physician over time (Bovbjerg \& Petronis 1994).

In our setting there was substantial positive serial correlation in the physicianlevel aggregates series and significant unobserved surgeon-level effects. Controlling for these with an assumed first-order auto-regressive function error structure and a surgeon fixed effects panel model, we found no significant relationship between the lagged flows of claim events and subsequent surgeon caseload, payor mix or ex ante patient risk.

Finally, we also found no differences between analyses restricted to patients in the 1998-2003 period or to the $2004-2006$ period. The latter period marked the institution of damages caps and other tort law reforms that passed Florida's state house in the final months of 2003. This may be due to the long tail of existing claims not bound by the new law; future re-analysis may show that claims first reported after the law change did have an impact on behavior. In other unreported analysis, we repeated all the charges analyses using Winsorized charges to remove the influence of far outliers, but results remained qualitatively unchanged.

\section{CONCLUSIONS AND DISCUSSION}

Our study failed to show that cardiac surgeons, practicing in Florida over a recent nine-year period, increased the intensity of or otherwise changed attributes of the healthcare services they rendered in response to a recent malpractice claim, suit, or settlement. 
Our analytical strategy attempted to identify such practices off of substantial variation across surgeons in the flow of claim events, inferring surgeon behavior off of changes in patient-level outcomes, risk, and payor status or hospital charges. We found very modest evidence of decreases in patient charges following final dispositions in favor of a surgeon, and unfavorable changes in patient payor mix following dispositions against a surgeon. There were no statistically persuasive changes in patient costs or outcomes associated with private reports.

These findings have a number of possible explanations. First, it is possible that the physicians do respond to the initiation of malpractice claims but exhibit a response that cannot easily be discerned even in such a large and long panel dataset. That is, the 'impulse response function' associated with an allegation of malpractice may be too muted. This could occur, for example, if the 'signal' of an allegation is too weak or too diffuse, or if provider patterns of practice resist rapid change.

Relatedly, surgeons might anticipate the threat of a tort action and thus adjust their levels of care - and their provision of defensive medicine-before any malpractice claim is filed. Thus, a behavioral change cannot be detected because physiciansregardless of whether an action is filed against them-operate within the shadow of the tort system.

Alternatively, malpractice claims might be sufficiently pervasive-or the 'signal' of an allegation in its identification of a particular surgeon might be too weak or imprecise - that many physicians in our sample believe that their conduct cannot affect the likelihood of a subsequent tort action. We note that in the three major east coast counties in Florida, 94\% of cardiovascular/thoracic surgeons have been sued, with 'an 
average of 2.1 past lawsuits each..., an average of 1.5 lawsuits pending and an average total of 3.6 lawsuits each so far in their career' (Palmisano 2004, p10).

Under this perspective, the uncertainty and imprecision of malpractice law-i.e. its inability to target only physicians who act negligently-impose significant social costs, including but not limited to pervasive defensive medicine. Similarly, the problem of determining negligence when multiple parties (e.g. an independent physician and a hospital) both dilutes the incremental legal liability attributable to the surgeon and creates a cloud of potential liability within collaborative conduct.

Such collaboration in medical care-and in producing medical errors-is common. In an analysis of patient claims alleging general surgical errors, $62 \%$ of errors involved more than one physician (Rogers et al., 2006). Collaborative conduct also invites invoking flexible doctrines such as 'apparent authority' liability and vicarious liability, which further obscure the allocation of liability. Consequently, surgeons might seek to decrease their expected liability by coordinating care with other legal entities even though such coordination often leads to lower quality of care.

The specialist surgical literature documents adverse patient and hospital outcomes associated with increased hand-offs and blurring of responsibility in multi-specialty teams (Williams et al., 2007; Rogers et al., 2006). Greenberg et al. (2007) identify serious communications breakdowns as typically involving verbal communication between a dyad comprising the senior surgical staff and another caregiver. Such related concerns over the fragmentation of medical care (Elhauge, 2010) and the imprecision of malpractice law have convinced many to seek enterprise liability tort reforms (Havighurst, 2000; Arlen \& McLeod, 2003). 
Finally, it is also possible that provider practice patterns exhibit such persistence that even correctly perceived informative signals are not able to drive change rapidly enough. The extensive literature on small-area variations in physician behavior is consistent with highly persistent idiosyncratic physician behavior. A long stream of work has looked at how practice patterns persist, and how peers, guidelines and other source of information may change these (Escarce, 1997, Valente \& Davis, 1999; Majumdar et al, 2002; 2004). Research on peer effects and key opinion leadership in healthcare delivery also suggests the difficulty of changing the practices of individual physicians (Berwick, 2003; Frank \& Zeckhauser, 2007). Our strategy explicitly assumes that events in the prior twelve months are able to affect change, but this may simply be too short a period to observe changes in physician conduct. This might suggest that the malpractice system does a poor job of deterring negligent conduct, even if it still might play an insurance role by providing compensation to injured parties.

Our study has several important limitations. We narrowly focus on one treatment within one specialty within one state. Yet this is a disease area where past research has found some evidence for defensive medicine identified off of reform (Kessler \& McClellan, 1996; 1997) and a state where recent research (Dranove et al, 2008) has demonstrated some behavioral changes among obstetricians following suits.

On the other hand, our focus on one state blurs well-known small area variations (Wennberg \& Cooper 1999; Huesch 2010) in patient outcomes and similar variations in claiming frequencies related to family income (Hart \& Peters 2008) or the level of expected damages related to county poverty rates or income inequality (Kohler-Hausman 2011). While we controlled for hospital-level fixed effects that are likely closely 
correlated with such small area-level effects, the effect of other related but omitted variables is not known.

Our data on claims is a right-censored sample. Given the mean four year period between alleged injury and final disposition, there are likely to be some open claims related to our panel not captured in the OIR data through November 2009. Additional ascertainment bias may exist if surgeons who 'go bare' (i.e. do not carry malpractice insurance and accept the risk of bankruptcy) give rise to unobserved claims. A related limitation of our data is that we do not observe events such as early offers of settlement occurring between initial notification of a claim and subsequent events. There is some conflicting empirical evidence whether such early offers may reduce defense costs (Black et al 2009). Our data was unable to capture this claim-level granularity.

The Florida Medical Association additionally cautions that "the settlement of malpractice claims occurs for a variety of reasons, which do not necessarily reflect negatively on the professional competence or conduct of the individual provider or institution. Payment of a claim should not be a presumption that malpractice has occurred. Physicians often have little control over whether the insurance company pays an award.” (Florida Medical Association)

While our data on hospital charges seem a noisy but unbiased proxy for treatment intensity, they are clearly upper bounds on actual payments. Thus we do not actually know the estimated changes in per patient payments associated with the estimated changes in per patient charges. A related major limitation is that we do not observe physician charges. Our outcomes are in-hospital only, and our estimates of no changes in patient outcomes might change if we looked at 30 day mortality or 1 year survival. 
We fail to reject the hypothesis that hidden costs, such as those imposed by the reporting of a malpractice claim, do not induce physicians to prescribe additionally defensive and costly care. We additionally fail to detect whether observable costs, such as the filing of a malpractice lawsuit or the release of a malpractice settlement, similarly affect physician behavior. We interpret the results from our null study and those in other recent articles (Sloan \& Schadle, 2009; Morrisey et al., 2008; Gimm, 2010) to suggest that malpractice claims have little effect on physician behavior and healthcare costs.

Perhaps this is because physicians operate within the shadowed threat of malpractice claims before any claims or suits are filed against them, such that they cannot provide additionally defensive medicine following a claim, suit, or judgment. This would suggest that malpractice claims might not exacerbate defensive medicine because such defensive over-provision of care is already widespread. Alternatively, physicians might be unresponsive to malpractice actions because physician behavior is inflexible and unresponsive to the threat of liability. This would suggest that defensive medicine might not be as pervasive as tort reformers might think, and that the tort system is a poor device to incent physicians and improve healthcare quality. Both of these conclusions are observationally equivalent.

Well-intentioned tort law reform may thus reduce the costs of negligence and thus reduce malpractice insurance premiums, but there is little evidence to suggest it affects outcomes in the healthcare delivery and financing markets. Changing practice patterns through other financial incentives, information (e.g. on cost, effectiveness, evidence bases), peer review, and judicious implementation of technology-enabled quality controls, audits and decision support may be promising policy alternatives. 


\section{REFERENCES}

Adams, J. L. \& S. Garber (2007) "Reducing Medical Malpractice by Targeting Physicians Making Medical Malpractice Payments," J. of Empirical Legal Studies 4: $185-222$.

Arlen, J., \& W.B. MacLeod (2003) "Malpractice Liability for Physicians and Managed Care Organizations," New York University Law Review 78(1929)

Avraham, R. (2007) “An Empirical Study of the Impact of Tort Reforms on Medical Malpractice Settlement Payments," Journal of Legal Studies 36(2): 183-229

Baicker, K., E.S. Fisher \& A. Chandra (2007) "Malpractice Liability Costs and the Practice of Medicine in the Medicare Program," Health Affairs 26(3): 841-852.

Berwick, D.M. (2003) “Disseminating Innovations in Health Care," Journal of the American Medical Association 289:1969-1975.

Black, B., D. A. Hyman, C. Silver \& W.M. Sage (2008) "Defense Costs and Insurer Reserves in Medical Malpractice and Other Personal Injury Cases: Evidence from Texas, 1988-2004," Am Law Econ Rev 10(2): 185-245

Black, B., D. A. Hyman \& C. Silver (2009) “The Effects of 'Early Offers' in Medical Malpractice Cases: Evidence from Texas," Journal of Empirical Legal Studies 6: $723-767$.

Bovbjerg, R. R., \& K. R. Petronis (1994) “The Relationship Between Physicians' Malpractice Claims History and Later Claims. Does the Past Predict the Future?" J. of the American Medical Association 272(1421) 
Bovbjerg, R.R. \& L.R. Tancredi (2005) 'Liability Reform Should Make Patients Safer: "Avoidable Classes Of Events" Are A Key Improvement," J Law Med Ethics 33: $478-500$

Congressional Budget Office. (2004) "Limiting Tort Liability for Medical Malpractice," Washington, D.C. Available at http://www.cbo.gov/ftpdocs/49xx/doc4968/01-08MedicalMalpractice.pdf

Cline, R.E., \& C.J. Pepine (2004) “Medical Malpractice Crisis: Florida’s Recent Experience," Circulation 109: 2936-2938

Cranberg, L. D., T. H. Glick \& L. Sato (2007) "Do the Claims Hold Up? A Study of Medical Negligence Claims Against Neurologists," Journal of Empirical Legal Studies 4: 155-162.

Currie, Janet, \& W. Bentley Macleod (2008) “First Do No Harm? Tort Reform and Birth Outcomes," Quarterly J. of Economics 123(795).

Danzon, P.M. (2000) “Liability for Medical Malpractice.” In Handbook of Health Economics, Vol 1B, edited by A. J. Culyer and J. P. Newhouse. 1339-404. Amsterdam: Elsevier.

Dhankhar, P., M. M. Khan \& S. Bagga (2007) "Effect of Medical Malpractice on Resource Use and Mortality of AMI Patients," J. of Empirical Legal Studies 4: 163183

Dranove, D., S. Ramanarayanan, \& Y. Watanabe (2008) "Changes in the Demand for Physician Services Subsequent to Negligence: Volume and Composition Effects," Working paper, Northwestern University Law School 
Dranove, D., \& A. Gron (2005) "Effects of the Malpractice Crisis on Access to and Incidence of High-Risk Procedures: Evidence from Florida," Health Affairs 24(3): 802-810.

Eagle, K.A., R.A. Guyton, R. Davidoff, et al. (2004) “ACC/AHA 2004 Guideline Update for Coronary Artery Bypass Graft Surgery,” Available at: http://www.acc.org/clinical/guidelines/cabg/cabg.pdf.

Elhauge, E. (2010) "The Fragmentation of U.S. Health Care: Causes and Solutions," Oxford University Press.

Escarce, J.J. (1997) “Externalities in Hospitals and Physician Adoption of a New Surgical Technology: An Exploratory Analysis," J. of Health Economics 15(6), 715-734

Florida Medical Association (2007) “Statement," Available at http://www.floir.com/Liability/

Florida Office of Insurance Regulation (2007) "Report of Commissioner Kevin McCarthy on Medical Malpractice Rates in Florida April 2007,’ Available from www.flfds.com

Florida Office of Insurance Regulation (2007) “Annual Report: Medical Malpractice Financial Information Closed Claim Database and Rate Filings," Available from www.flfds.com

Frank, R.G., \& R.J. Zeckhauser (2007) “Custom-made Versus Ready-to-wear Treatments: Behavioral Propensities in Physicians' Choices," J. of Health Economics 26: 1101-1127. 
Gimm, G.W. (2010) “The Impact of Malpractice Liability Claims on Obstetrical Practice Patterns," Health Services Research 45(1): 195-211

Glassman, P.A., J.E. Rolph, L.P. Peterson, et al. (1996) 'Physicians’ personal malpractice experiences are not related to defensive clinical practices," J Health Polit Policy Law 21: 219.

Greenberg, C.C., S.E. Regenbogen, D.M. Studdert et al. (2007) "Patterns of Communications Breakdowns Resulting in Injury to Surgical Patients," J. of American College of Surgery 204: 533-540.

Hart, K. D. \& P. G. Peters (2008) “Cultures of Claiming: Local Variation in Malpractice Claim Frequency,” J. of Empirical Legal Studies 5: 77-107.

Havighurst, C.C. (2000) "Vicarious Liability: Relocating Responsibility for the Quality of Medical Care," American J. of Law and Medicine 26(7)

Hellinger FJ, \& W.E. Encinosa (2006) "The impact of state laws limiting malpractice damage awards on health care expenditures," American J. Public Health 2006;96: $1375-1381$

Huesch, M.D. (2010) "Payment policy by measurement of health care spending and outcomes," J. of American Medical Association 303(23):2405-2406

Hyman, D.A. (2007) “Improving the Evidence/Advocacy Ratio in Medical Malpractice reform," Health Affairs 26(1): 289-290.

Kessler, D.P., \& M.B. McClellan (1996) "Do Doctors Practice Defensive Medicine?" Quarterly J. of Economics 111(2): 353-390. 
Kessler, D.P., \& M.B. McClellan (1997) "The Effects of Malpractice Pressure and Liability Reforms on Physicians' Perceptions of Medical Care," Law and Contemporary Problems 60: 81-106.

Kiser, R. L., M. A. Asher \& B. B. McShane (2008) "Let's Not Make a Deal: An Empirical Study of Decision Making in Unsuccessful Settlement Negotiations," J. of Empirical Legal Studies 5: 551-591.

Kohler-Hausmann, I. (2011) "Community Characteristics and Tort Law: The Importance of County Demographic Composition and Inequality to Tort Trial Outcomes," J. of Empirical Legal Studies 8: 413-447

Landon, B.E., J. Reschovsky, M. Reed \& D. Blumenthal (2001) “Personal, Organizational, and Market Level Influences on Physicians’ Practice Patterns," Medical Care 39(8): 889-905

Majumdar, S.R., F.A. McAlister, \& C.D. Furberg (2004) “From Knowledge to Practice in Chronic Cardiovascular Disease: a Long and Winding Road," J. of American College of Cardiology 43, 1738-1742

Majumdar, S.R., W.-C. Chang, \& P.W. Armstrong (2002) “Do the Investigative Sites that Take Part in a Positive Clinical Trial Translate that Evidence Into Practice?" American J. of Medicine 113, 140-145

Mello, M.M., C.N. Kelly, \& T.A. Brennan (2005) "Fostering rational regulation of patient safety," J Health Polit Policy Law 30: 375-426

Mello, M.M., D.M. Studdert, C.M. DesRoches, et al. (2004) “Caring for Patients in a Malpractice Crisis: Physician Satisfaction and Quality of Care," Health Affairs 23(4): 42-53. 
Morrisey, M.M., M.L. Kilgore, \& L.J. Nelson (2008) "Medical Malpractice Reform and Employer-Sponsored Health Insurance Premiums," Health Services Research 43(6): 2124-2142.

Nelson, L.J., M.L. Kilgore, \& M.A. Morrisey (2007) “Damage Caps in Medical Malpractice Cases,” Milbank Quarterly 85(2): 259-86.

Palmisano, D.J. (2004) “The Hidden Cost of Medical Liability Litigation,” Annals of Thoracic Surgery 78: 9-13.

Rogers, S.O., A.A. Gawande, M. Kwaan, et al. (2006) “Analysis of Surgical Errors in Closed Malpractice Claims at 4 Liability Insurers," Surgery 140: 25-33.

Rothman, K.J. (1990) "No Adjustments Are Needed For Multiple Comparisons," Epidemiology 1:43-46.

Shavell, S. (1984) “A Model of the Optimal Use of Liability and Safety Regulation," Rand J. of Economics 15: 271-280.

Sloan, F.A. (2003) "Public Medical Malpractice Insurance," The Pew Charitable Trusts. Available at www.medliabilitypa.org.

Sloan, F.A., \& J.H. Shadle (2009) "Is There Empirical Evidence for 'Defensive Medicine'? A Reassessment," J. of Health Economics 28: 481-491.

Studdert, D.M., M.M. Mello, \& T.A. Brennan (2005) “Medical Malpractice,” New England J. of Medicine 350: 283-292

Studdert, D.M., M. Michelle, A. Gawande, et al (2006) “Claims, Errors, and Compensation Payments in Medical Malpractice Litigation," New England J. of Medicine 3542024. 
Yang, Y. T., D.M. Studdert, S.V. Subramanian, \& M.M. Mello (2008) “A Longitudinal Analysis of the Impact of Liability Pressure on the Supply of ObstetricianGynecologists,” J. of Empirical Legal Studies 5: 21-53

Valente, T.W., \& R.L. Davis (1999) “Accelerating the Diffusion of Innovations Using Opinion Leaders," Annals of the American Academy of Political and Social Science $566,55-67$

Waters, T.M., P.B. Budetti, G. Claxton, \& J.P. Lundy (2007) "Impact of State Tort Reforms on Physician Malpractice Payments," Health Affairs 26(2): 500-509.

Wennberg, J.E., \& M.M. Cooper (1999) “The Dartmouth Atlas of Health Care. Chicago: Dartmouth Medical School and American Hospital" $5^{\text {th }}$ Edition Williams, R.G., R. Silverman, C. Schwind, et al. (2007) “Surgeon Information Transfer and Communication Factors Affecting Quality and Efficiency of Inpatient Care," Annals of Surgery 245: 159-169. 
Table 1: Claim-level Events

\begin{tabular}{|c|c|c|}
\hline & & Counts \\
\hline Alleged occurences & 211 & \\
\hline Reported claims, of which: & 211 & \\
\hline Led to filed suit, of which: & & 165 \\
\hline Dropped/no court proceedings recorded & & 21 \\
\hline Settled for defendant & & 2 \\
\hline Settled for plaintiff & & 0 \\
\hline Did not proceed & & 19 \\
\hline Arbitrated & & 1 \\
\hline Found for defendant & & 1 \\
\hline Found for plaintiff & & 0 \\
\hline Settled & & 113 \\
\hline Settled for defendant & & 14 \\
\hline Settled for plaintiff & & 99 \\
\hline Went to court & & 30 \\
\hline Found for defendant & & 14 \\
\hline Found for plaintiff & & 2 \\
\hline Dropped/did not proceed & & 14 \\
\hline Did not lead to suit filed, of which: & & 46 \\
\hline Arbitrated & & 2 \\
\hline Found for defendant & & 0 \\
\hline Found for plaintiff & & 2 \\
\hline Dropped/no court proceedings recorded & & 14 \\
\hline Settled for defendant & & 0 \\
\hline Settled for plaintiff & & 0 \\
\hline Did not proceed & & 14 \\
\hline Settled & & 30 \\
\hline Settled for defendant & & 7 \\
\hline Settled for plaintiff & & 23 \\
\hline Closed claims & 211 & \\
\hline
\end{tabular}

Note: Claim-level counts for analysis dataset. 
Figure 1: Timeline and Typical Sequence of Events Analyzed

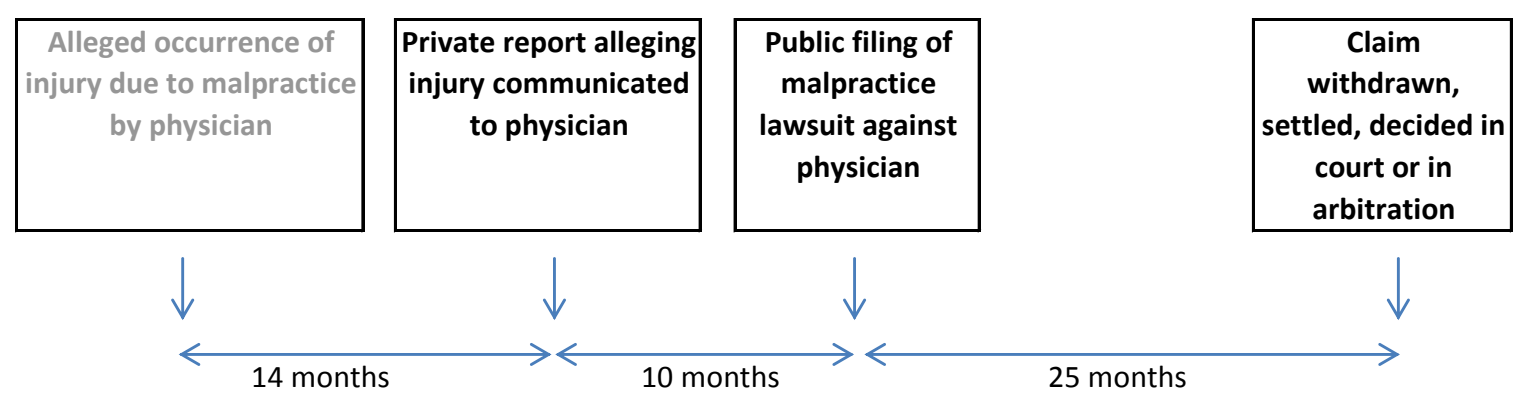

Note: This sequence of events is only observed if a claim is made (some allegations are resolved through pre-emptive settlements and are not recorded by the OIR database) and the claim was closed by November, 2009, when we accessed the Closed Claims OIR database. Values in months indicate mean durations in our data. 
Table 2: Surgeon-level Focal Independent Variables

\begin{tabular}{lcccc}
\hline & Mean & Std. Dev. & Min & Max \\
\hline Surgeon's lagged CABG cases (\#, prior 4 quarters) & 95.2 & 68.5 & 3 & 351.5 \\
Surgeon's lagged events (\#, prior 4 quarters) & & & & \\
$\quad$ Alleged occurences & 0.06 & 0.12 & 0 & 0.94 \\
Reported claims & 0.05 & 0.10 & 0 & 0.73 \\
Filed suits & 0.05 & 0.09 & 0 & 0.60 \\
Closed claims (against surgeon) & 0.03 & 0.07 & 0 & 0.57 \\
Closed claims (for surgeon) & 0.02 & 0.05 & 0 & 0.30 \\
\hline
\end{tabular}

Note: Surgeon-level unweighted means for 296 surgeons in regressions. 
Figure 2a: Histogram of Surgeon-Level Lagged Claim Events, Alleged Incidents

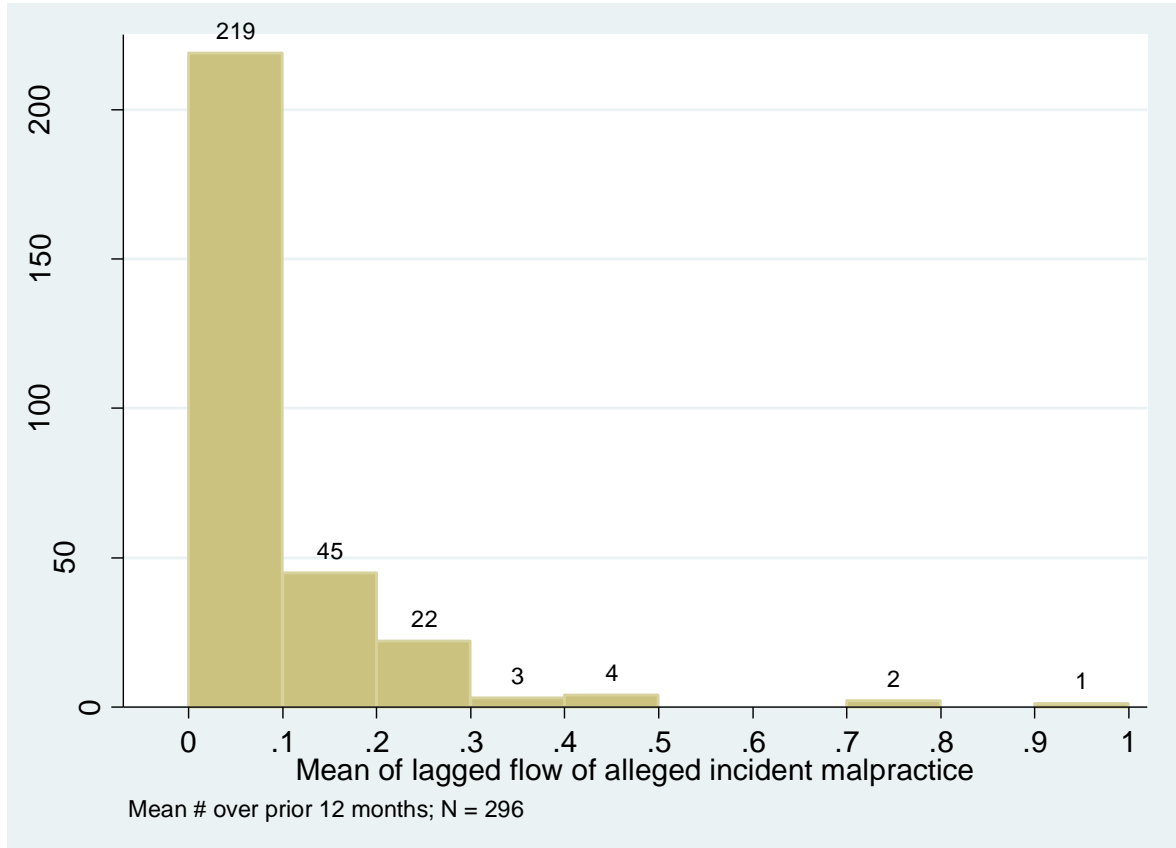

Figure 2b: Reported Claims

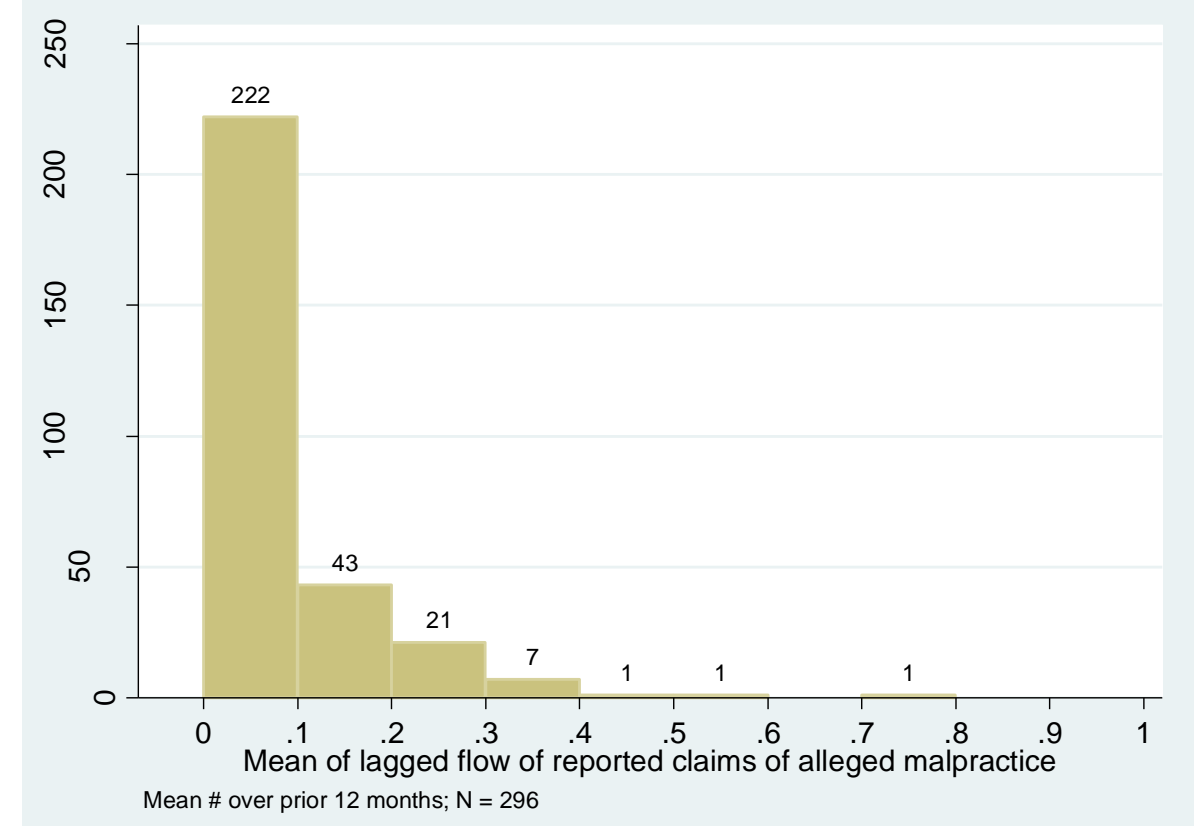


Figure 2c: Filed Suits

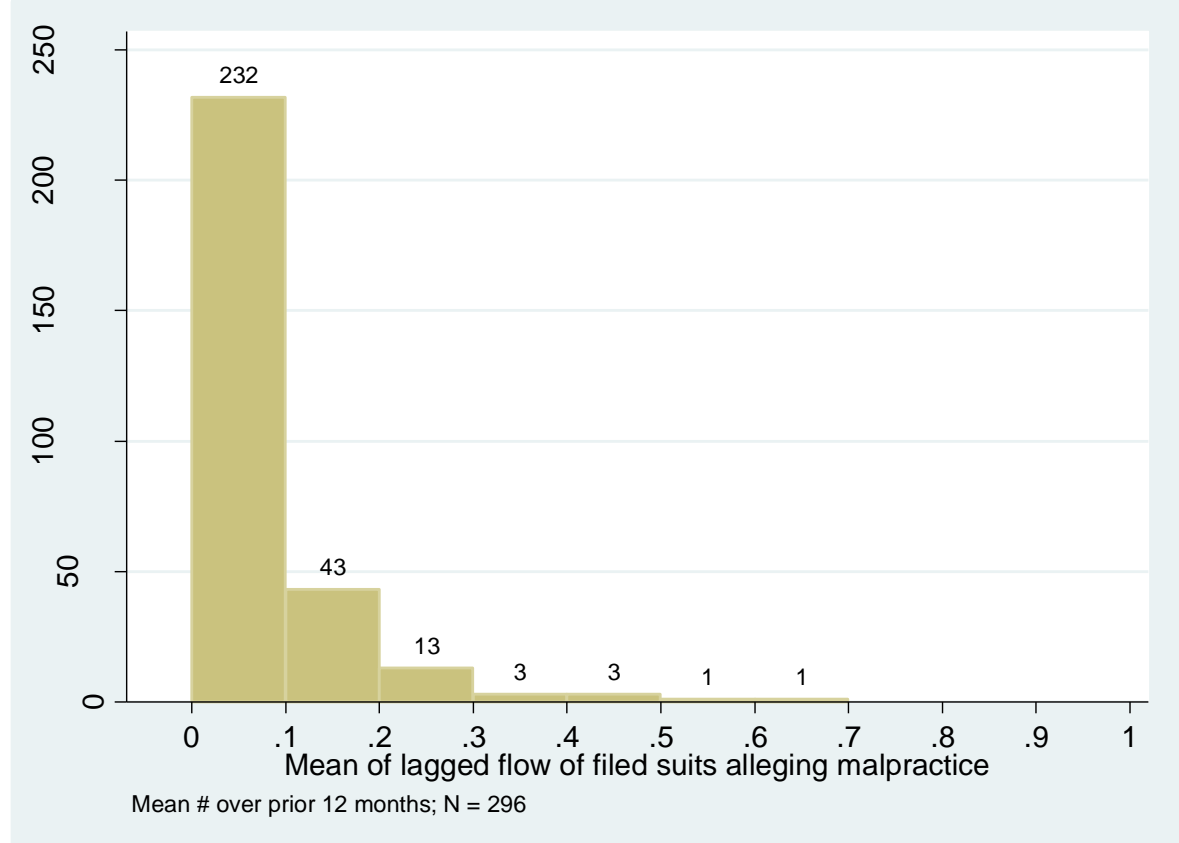

Figure 2d: Dispositions Against Surgeon

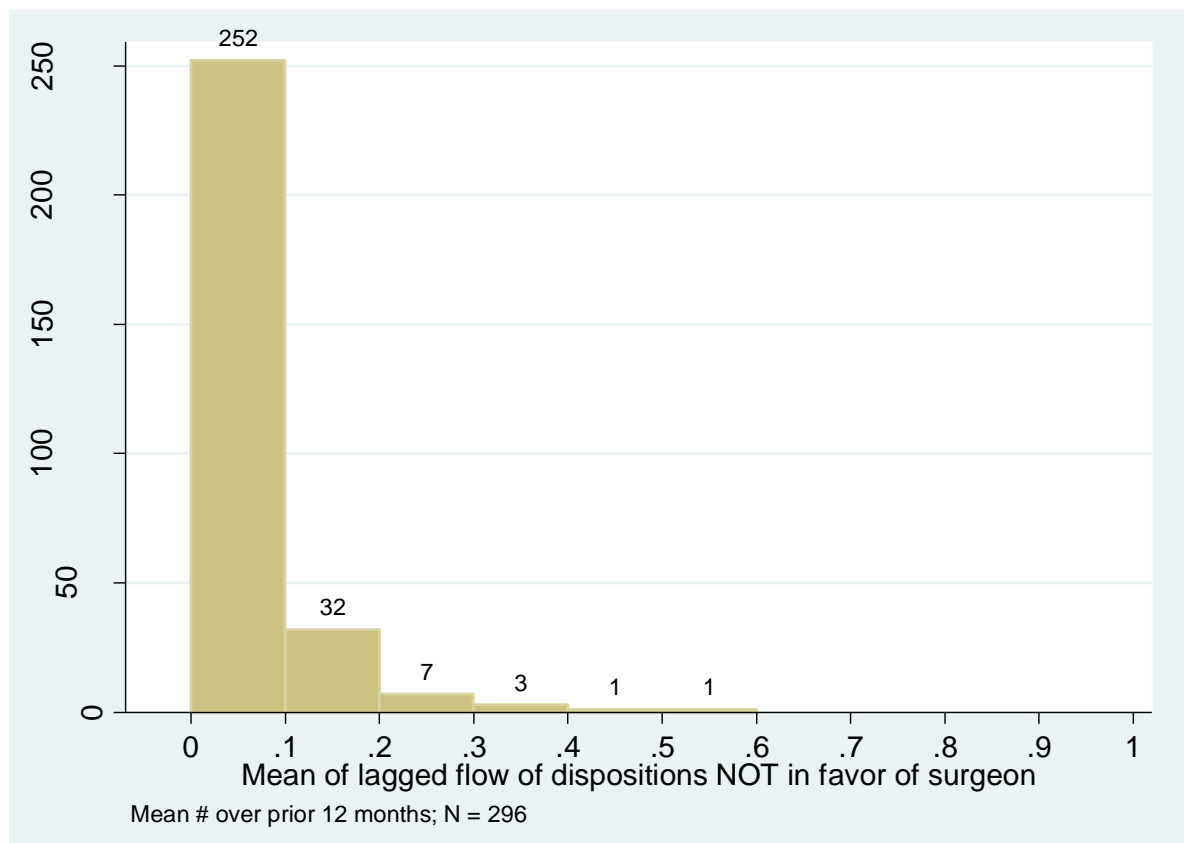


Figure 2e: Dispositions In Favor of Surgeon

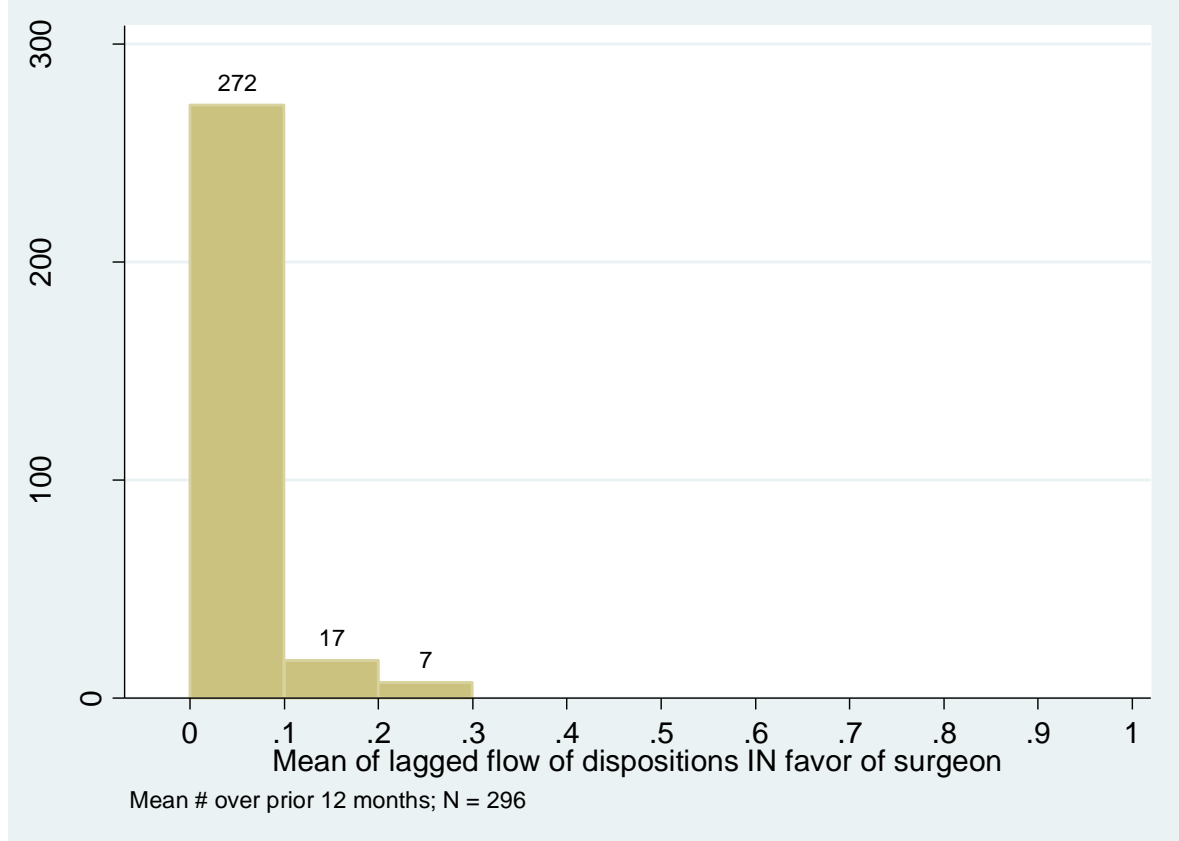


Table 3: Patient-weighted Dependent and Focal Independent Variables

\begin{tabular}{|c|c|c|c|}
\hline & Mean & Std. Dev. & Median ( $25-75$ centiles) \\
\hline \multicolumn{4}{|l|}{ Ex ante variables (\%) } \\
\hline Expected in-hospital mortality & 3.9 & 6.6 & \\
\hline Payor status: Medicare & 50.4 & 50.0 & \\
\hline PPO & 12.6 & 33.2 & \\
\hline $\mathrm{HMO}$ & 12.0 & 32.5 & \\
\hline MedicareMC & 11.8 & 32.2 & \\
\hline Indemnity & 4.2 & 20.1 & \\
\hline Medicaid & 2.1 & 14.2 & \\
\hline Medicaid HMO & 0.8 & 9.0 & \\
\hline \multicolumn{4}{|l|}{ Outcomes (\%) } \\
\hline Prolonged mech. Ventilation & 3.0 & 16.9 & \\
\hline In-hospital mortality & 3.8 & 19.1 & \\
\hline Discharged not directly/alone home & 21.3 & 40.9 & \\
\hline Length of stay (days) & 10.3 & 8.8 & $8(6-12)$ \\
\hline \multicolumn{4}{|l|}{ Hospital itemized charges (\$) } \\
\hline Total & 99,432 & 81,401 & $77,816(55,489-116,319)$ \\
\hline Operating room only & 18,993 & 14,078 & $14,661(10,056-23,260)$ \\
\hline Non-operating room & 80,439 & 75,438 & $61,130(41,964-93,333)$ \\
\hline Surgeon's lagged CABG cases (\#, prior 4 quarters) & 168.8 & 76.3 & \\
\hline \multicolumn{4}{|l|}{ Surgeon's lagged events (\#, prior 4 quarters) } \\
\hline Alleged occurences & 0.08 & 0.28 & \\
\hline Reported claims & 0.09 & 0.31 & \\
\hline Filed suits & 0.07 & 0.28 & \\
\hline Closed claims (against surgeon) & 0.05 & 0.22 & \\
\hline Closed claims (for surgeon) & 0.03 & 0.18 & \\
\hline
\end{tabular}

Note: Patient-weighted means for 185,849 observations in regressions. Twelve months lagged predictors explains reduction in observations from total validated 220,843 admissions. 
Table 4: Summary Statistics for Control Covariates

\begin{tabular}{|c|c|c|}
\hline & Mean & Std. Dev. \\
\hline Age (years) & 67.5 & 10.7 \\
\hline Female & 29.0 & 45.4 \\
\hline Non-white & 9.4 & 29.1 \\
\hline Emergency & 25.0 & 43.3 \\
\hline Transfer & 42.4 & 49.4 \\
\hline Government payor & 65.9 & 47.4 \\
\hline County - bachelor degree & 24.8 & 5.4 \\
\hline Elderly & 18.1 & 6.0 \\
\hline Below poverty level & 12.4 & 2.7 \\
\hline Family income median (\$) & 42,904 & 4,647 \\
\hline Known coronary artery disease & 95.0 & 21.8 \\
\hline Hypertension & 54.9 & 49.8 \\
\hline Dysrhythmiae & 38.6 & 48.7 \\
\hline Unstable angina & 35.9 & 48.0 \\
\hline Diabetes mellitus & 29.4 & 45.6 \\
\hline Acue myocardial infarction & 25.9 & 43.8 \\
\hline Congestive heart failure & 23.8 & 42.6 \\
\hline Chronic obstructive lung disease & 20.0 & 40.0 \\
\hline Fluid disorder & 14.4 & 35.1 \\
\hline Concurrent valve operation & 13.7 & 34.4 \\
\hline Coagulopathy & 10.7 & 31.0 \\
\hline Angina & 10.6 & 30.8 \\
\hline Complications of hypertension & 7.3 & 26.1 \\
\hline Conduction disorder & 6.3 & 24.2 \\
\hline Ventricular tachycardia & 4.9 & 21.6 \\
\hline Carditis & 2.9 & 16.7 \\
\hline Pumonary artery heart disease & 2.7 & 16.2 \\
\hline Aneurysms & 2.4 & 15.3 \\
\hline Cerebrovascular disease & 1.7 & 13.0 \\
\hline Chronic kidney disease & 1.7 & 12.8 \\
\hline Liver disease & 1.1 & 10.3 \\
\hline Transient ischemic attacks & 0.4 & 6.2 \\
\hline 2000 & 14.6 & 35.3 \\
\hline 2001 & 14.1 & 34.8 \\
\hline 2002 & 13.3 & 34.0 \\
\hline 2003 & 11.9 & 32.4 \\
\hline 2004 & 11.6 & 32.0 \\
\hline 2005 & 10.8 & 31.0 \\
\hline 2006 & 9.6 & 29.4 \\
\hline
\end{tabular}

Note: Patient-weighted means (\%, unless otherwise indicated) for 185,849 observations in regressions. Twelve months lagged predictors explains reduction in observations from total validated 220,843 admissions. Excluded calendar year indicator: 1999. County ecological variables merged in from 2005 Census Bureau data for Florida county of patient's residence, set to mean where out of state or missing. 
Table 5: Regression Results for Impact of Lagged Surgeon Claim Events on Patient Risk, Hospital Charges and Outcomes

\begin{tabular}{|c|c|c|c|c|c|c|c|}
\hline & $\begin{array}{l}\text { Expected in- } \\
\text { hospital } \\
\text { mortality }\end{array}$ & $\begin{array}{l}\text { Log Length } \\
\text { of stay }\end{array}$ & $\begin{array}{l}\text { Log OR } \\
\text { charges }\end{array}$ & $\begin{array}{l}\text { Log Non- } \\
\text { OR charges }\end{array}$ & $\begin{array}{l}\text { Ventilation } \\
>96 \text { hours }\end{array}$ & $\begin{array}{l}\text { Died in- } \\
\text { hospital }\end{array}$ & $\begin{array}{c}\text { Discharge } \\
\text { not } \\
\text { directly } \\
\text { home }\end{array}$ \\
\hline Patient controls & \multicolumn{2}{|c|}{ Included in all specifications } & & & & & \\
\hline Calendar and facility fixed effects & $"$ & & & & & & \\
\hline Caseload, last 4 quarters & $\begin{array}{c}0.0000 \text { 9 } \\
(0.0000)\end{array}$ & $\begin{array}{l}-0.0004 \text { *** } \\
(0.0001)\end{array}$ & $\begin{array}{l}-0.0006 \text { *** } \\
(0.0001)\end{array}$ & $\begin{array}{l}-0.0004^{* * *} \\
(0.0001)\end{array}$ & $\begin{array}{l}-0.0001 * * * \\
(0.0000)\end{array}$ & $\begin{array}{l}-0.0001 * * * \\
(0.0000)\end{array}$ & $\begin{array}{l}-0.0002 \text { *** } \\
(0.0000)\end{array}$ \\
\hline \multicolumn{8}{|l|}{ Lagged \# events, last 4 quarters } \\
\hline Alleged incident malpractice & $\begin{array}{r}0.0002 \\
(0.0003)\end{array}$ & $\begin{array}{r}0.0044 \\
(0.0061)\end{array}$ & $\begin{array}{r}0.0092 \\
(0.0185)\end{array}$ & $\begin{array}{r}-0.0115 \\
(0.0107)\end{array}$ & $\begin{array}{r}0.0002 \\
(0.0016)\end{array}$ & $\begin{array}{r}0.0009 \\
(0.0019)\end{array}$ & $\begin{array}{r}-0.0051 \\
(0.0046)\end{array}$ \\
\hline Reported claims & $\begin{array}{r}0.0001 \\
(0.0003)\end{array}$ & $\begin{array}{r}-0.0037 \\
(0.0050)\end{array}$ & $\begin{array}{r}0.0154 \\
(0.0182)\end{array}$ & $\begin{array}{r}0.0043 \\
(0.0110)\end{array}$ & $\begin{array}{r}-0.0013 \\
(0.0016)\end{array}$ & $\begin{array}{r}-0.0024 \\
(0.0015)\end{array}$ & $\begin{array}{r}-0.0037 \\
(0.0065)\end{array}$ \\
\hline Filed suits & $\begin{array}{r}-0.0004 \\
(0.0003)\end{array}$ & $\begin{array}{r}-0.0008 \\
(0.0083)\end{array}$ & $\begin{array}{r}-0.0033 \\
(0.0173)\end{array}$ & $\begin{array}{r}-0.0037 \\
(0.0093)\end{array}$ & $\begin{array}{r}-0.0004 \\
(0.0015)\end{array}$ & $\begin{array}{c}0.0030 \text { 9 } \\
(0.0017)\end{array}$ & $\begin{array}{r}-0.0016 \\
(0.0050)\end{array}$ \\
\hline Closed claims (against surgeon) & $\begin{array}{r}0.0001 \\
(0.0003)\end{array}$ & $\begin{array}{r}0.0019 \\
(0.0073)\end{array}$ & $\begin{array}{r}0.0123 \\
(0.0262)\end{array}$ & $\begin{array}{c}0.0200 \text { ๆ } \\
(0.0113)\end{array}$ & $\begin{array}{r}0.0017 \\
(0.0023)\end{array}$ & $\begin{array}{r}0.0015 \\
(0.0031)\end{array}$ & $\begin{array}{r}-0.0056 \\
(0.0068)\end{array}$ \\
\hline Closed claims (for surgeon) & $\begin{array}{r}-0.0002 \\
(0.0005)\end{array}$ & $\begin{array}{r}0.0087 \\
(0.0097)\end{array}$ & $\begin{array}{r}-0.0278 \\
(0.0275)\end{array}$ & $\begin{array}{c}-0.0289 * \\
(0.0136)\end{array}$ & $\begin{array}{r}-0.0004 \\
(0.0029)\end{array}$ & $\begin{array}{c}0.0052 \\
(0.0024)\end{array}$ & $\begin{array}{r}-0.0005 \\
(0.0075)\end{array}$ \\
\hline$R^{2}$ & $76.5 \%$ & $38.6 \%$ & $71.5 \%$ & $64.6 \%$ & $8.1 \%$ & $9.0 \%$ & $24.8 \%$ \\
\hline Observations & 185,849 & 185,625 & 185,081 & 185,849 & 185,849 & 185,849 & 185,849 \\
\hline
\end{tabular}

Note: Regressions on column dependent variables. Estimates and (below) robust standard errors clustered by operating cardiac surgeon. Estimated parameters significant at $\left(^{* * *}\right) p<.001 ;\left(^{* *}\right) p<.01 ;\left(^{*}\right) p<.05$; and (9) $p<.10$. Twelve patient demographic and ecological covariates, 22 comorbidity covariates, 8 calendar year fixed effects and 74 facility fixed effects included in all specifications. Twelve months lagged predictors explains reduction in observations from total validated 220,843 admissions. 
Table 6: Regression Results for Impact of Lagged Surgeon Claim Events on Focal Patient Payor Status

\begin{tabular}{|c|c|c|c|c|c|c|c|}
\hline & PPO & HMO & FFS & $\begin{array}{l}\text { Medicare } \\
\text { MC }\end{array}$ & $\begin{array}{c}\text { Medicare } \\
\text { FFS }\end{array}$ & Medicaid & $\begin{array}{c}\text { Medicaid } \\
\text { HMO }\end{array}$ \\
\hline Patient controls & \multicolumn{3}{|c|}{ Included in all specifications } & & & & \\
\hline Calendar and facility fixed effects & $"$ & & & & & & \\
\hline Caseload, last 4 quarters & $\begin{array}{c}4.76 \mathrm{E}-05 * \\
(1.88 \mathrm{E}-05)\end{array}$ & $\begin{array}{r}1.43 \mathrm{E}-05 \\
(2.32 \mathrm{E}-05)\end{array}$ & $\begin{array}{l}-3.45 E-06 \\
(1.03 E-05)\end{array}$ & $\begin{array}{r}5.35 \mathrm{E}-05 \\
(5.40 \mathrm{E}-05)\end{array}$ & $\begin{array}{l}-3.10 E-06 \\
(6.33 E-05)\end{array}$ & $\begin{array}{l}-3.78 \mathrm{E}-05 * * * \\
(8.71 \mathrm{E}-06)\end{array}$ & $\begin{array}{l}-1.91 \mathrm{E}-05 * * \\
(6.36 \mathrm{E}-06)\end{array}$ \\
\hline \multicolumn{8}{|l|}{ Lagged \# events, last 4 quarters } \\
\hline Alleged incident malpractice & $\begin{array}{r}-0.0030 \\
(0.0025)\end{array}$ & $\begin{array}{r}0.0076 \\
(0.0050)\end{array}$ & $\begin{array}{c}-0.0040 * \\
(0.0018)\end{array}$ & $\begin{array}{r}0.0009 \\
(0.0061)\end{array}$ & $\begin{array}{r}0.0029 \\
(0.0057)\end{array}$ & $\begin{array}{l}-0.0023 \text { 9 } \\
(0.0013)\end{array}$ & $\begin{array}{r}0.0015 \\
(0.0021)\end{array}$ \\
\hline Reported claims & $\begin{array}{r}0.0011 \\
(0.0036)\end{array}$ & $\begin{array}{r}-0.0006 \\
(0.0045)\end{array}$ & $\begin{array}{r}-0.0005 \\
(0.0020)\end{array}$ & $\begin{array}{r}0.0048 \\
(0.0057)\end{array}$ & $\begin{array}{r}-0.0023 \\
(0.0043)\end{array}$ & $\begin{array}{r}0.0010 \\
(0.0012)\end{array}$ & $\begin{array}{l}-0.0027 \text { * } \\
(0.0012)\end{array}$ \\
\hline Filed suits & $\begin{array}{r}-0.0010 \\
(0.0030)\end{array}$ & $\begin{array}{c}0.0082 \text { ๆ } \\
(0.0048)\end{array}$ & $\begin{array}{r}-0.0016 \\
(0.0021)\end{array}$ & $\begin{array}{l}-0.0135 \text { ๆ } \\
(0.0071)\end{array}$ & $\begin{array}{c}0.0120 * \\
(0.0061)\end{array}$ & $\begin{array}{r}0.0004 \\
(0.0013)\end{array}$ & $\begin{array}{r}-0.0007 \\
(0.0012)\end{array}$ \\
\hline Closed claims (against surgeon) & $\begin{array}{l}-0.0085 * \\
(0.0041)\end{array}$ & $\begin{array}{c}0.0171 * \\
(0.0074)\end{array}$ & $\begin{array}{r}-0.0018 \\
(0.0021)\end{array}$ & $\begin{array}{r}-0.0083 \\
(0.0072)\end{array}$ & $\begin{array}{r}0.0012 \\
(0.0070)\end{array}$ & $\begin{array}{r}-0.0015 \\
(0.0013)\end{array}$ & $\begin{array}{r}-0.0016 \\
(0.0016)\end{array}$ \\
\hline Closed claims (for surgeon) & $\begin{array}{r}-0.0042 \\
(0.0080)\end{array}$ & $\begin{array}{r}0.0042 \\
(0.0083)\end{array}$ & $\begin{array}{r}-0.0034 \\
(0.0032)\end{array}$ & $\begin{array}{r}-0.0018 \\
(0.0118)\end{array}$ & $\begin{array}{r}0.0065 \\
(0.0099)\end{array}$ & $\begin{array}{r}0.0011 \\
(0.0017)\end{array}$ & $\begin{array}{r}-0.0004 \\
(0.0026)\end{array}$ \\
\hline $\begin{array}{l}\mathrm{R}^{2} \\
\text { Observations }\end{array}$ & $14.8 \%$ & $15.7 \%$ & $7.3 \%$ & $\begin{array}{r}13.3 \% \\
185,849\end{array}$ & $36.1 \%$ & $4.8 \%$ & $3.2 \%$ \\
\hline
\end{tabular}

Note: Linear probability model; regression on indicator for patient payor status. Estimates and (below) robust standard errors clustered by operating cardiac surgeon. Estimated parameters significant at $\left({ }^{* * *}\right) p<.001 ;(* *) p<.01 ;(*) p<.05$; and $(\mathbb{q}) p<.10$. Twelve patient demographic and ecological covariates, 22 comorbidity covariates, 8 year fixed effects and 74 facility fixed effects included. Note 'government payor' control omitted from all specifications. Twelve months lagged predictors explains reduction in observations from total validated 220,843 admissions. 